\title{
Effect of the revisit interval and temporal upscaling methods on the accuracy of remotely sensed evapotranspiration estimates
}

\author{
Joseph G. Alfieri ${ }^{1}$, Martha C. Anderson ${ }^{1}$, William P. Kustas ${ }^{1}$, and Carmelo Cammalleri ${ }^{2}$ \\ ${ }^{1}$ US Department of Agriculture, Agricultural Research Service, Hydrology and Remote Sensing Laboratory, \\ Beltsville, MD, USA \\ ${ }^{2}$ Joint Research Centre, European Commission, Ispra, Italy \\ Correspondence to: Joseph G. Alfieri (joe.alfieri@ars.usda.gov)
}

Received: 31 May 2016 - Published in Hydrol. Earth Syst. Sci. Discuss.: 4 July 2016

Revised: 2 December 2016 - Accepted: 7 December 2016 - Published: 5 January 2017

\begin{abstract}
Accurate spatially distributed estimates of actual evapotranspiration (ET) derived from remotely sensed data are critical to a broad range of practical and operational applications. However, due to lengthy return intervals and cloud cover, data acquisition is not continuous over time, particularly for satellite sensors operating at medium $(\sim 100 \mathrm{~m})$ or finer resolutions. To fill the data gaps between clear-sky data acquisitions, interpolation methods that take advantage of the relationship between ET and other environmental properties that can be continuously monitored are often used. This study sought to evaluate the accuracy of this approach, which is commonly referred to as temporal upscaling, as a function of satellite revisit interval. Using data collected at 20 Ameriflux sites distributed throughout the contiguous United States and representing four distinct land cover types (cropland, grassland, forest, and open-canopy) as a proxy for perfect retrievals on satellite overpass dates, this study assesses daily ET estimates derived using five different reference quantities (incident solar radiation, net radiation, available energy, reference ET, and equilibrium latent heat flux) and three different interpolation methods (linear, cubic spline, and Hermite spline). Not only did the analyses find that the temporal autocorrelation, i.e., persistence, of all of the reference quantities was short, it also found that those land cover types with the greatest ET exhibited the least persistence. This carries over to the error associated with both the various scaled quantities and flux estimates. In terms of both the root mean square error (RMSE) and mean absolute error (MAE), the errors increased rapidly with increasing return interval following a logarithmic relationship. Again, those land cover types with the greatest ET showed the largest errors. Moreover, using a
\end{abstract}

threshold of $20 \%$ relative error, this study indicates that a return interval of no more than 5 days is necessary for accurate daily ET estimates. It also found that the spline interpolation methods performed erratically for long return intervals and should be avoided.

\section{Introduction}

As one component of a complex network of interconnected processes, evapotranspiration (ET) is influenced by numerous factors such as available energy, soil moisture, vegetation density, and humidity (Farquhar and Sharkey, 1982; Van de Griend and Owe, 1994; Alves and Pereira, 2000; Alfieri et al., 2007). For example, the amount of energy available to drive ET depends on atmospheric properties, such as humidity and aerosol content, which influence atmospheric transmissivity (Brutsaert, 1975; Bird and Riordan, 1986). The available energy is also controlled by surface properties, such as the type and density of vegetation cover and soil moisture, which influence not only the surface albedo and emissivity (Wittich, 1997; Asner et al., 1998; Myneni et al., 1989; Song et al., 1999; Lobell and Asner, 2002), but also impact the amount of energy conducted into the ground (Friedl and Davis, 1994; Kustas et al., 2000; Abu-Hamdeh, 2003; Santanell and Friedl, 2003). Moreover, the magnitude of the moisture flux can vary over a range of timescales in response to changes in the environmental conditions influencing ET. One example of this, which has been pointed out by Williams et al. (2003), Scott et al. (2014), and others, is the rapid and often persistent change in ET in response to a rain event. 
Because it is a fundamental linkage between numerous biogeophysical and biogeochemical processes, accurate information regarding evapotranspiration (ET) is critical for a broad range of scientific and practical applications with significant social, economic, and environmental impacts. For example, reliable information about ET is essential for accurately forecasting weather and assessing the impacts of changing climate (Katul et al., 2012; Wang and Dickinson, 2012), monitoring and mitigating the adverse effects of extreme weather events such as drought (Anderson et al., 2007, 2011, 2016; Otkin et al., 2016), and identifying and predicting the changes in both the biogeographical characteristics of ecosystems and the services they provide in response to changing environmental conditions (Hawkins and Porter, 2003; Kreft and Jetz, 2007; Midgley et al., 2002). However, as pointed out by Seguin and Itier (1983), Abdelghani et al. (2008), and Anderson et al. (2012), among others, perhaps the most important application of ET data is in providing information critical to satisfying the competing demands for scare water resources.

Already, the competing demands for freshwater by agricultural, industrial, and urban consumers exceed the available supply for nearly one-third of the world's population (Qadir et al., 2003), and it is predicted that number will increase to more than two-thirds of the global population in the coming decades (Wallace, 2000; Vörösmarty et al., 2010). To meet the current and future demand for water, resource managers and other policymakers must make informed decisions regarding the needs of competing stakeholders when allocating limited water resources in order to maximize their effective use. In the case of irrigated agriculture, which is the largest consumer of freshwater and accounts for $1200 \mathrm{~km}^{3}$ or approximately $85 \%$ of annual current water use (Drooger et al., 2010; Thenkabail et al., 2010), the need for water is largely driven by evaporative loss. Thus, ET measurements are needed not only to monitor evaporative water loss and determine crop irrigation needs, but also to develop the irrigation techniques and management practices necessary to ensure the efficient use of water in agricultural environments (Howell, 2001; Schultz and Wrachien, 2002; Gordon et al., 2010; de Fraiture and Wichelns, 2010).

While in situ observations are invaluable for some of these applications, many of them require spatially distributed measures of ET at field to continental scales that cannot be supplied by the existing flux measurement infrastructure. Remote sensing-based approaches are the only viable means for monitoring ET over this continuum of scales (McCabe et al., 2008; Kalma et al., 2008; Gonzalez-Dugo et al., 2009). As discussed by Anderson et al. (2012), any comprehensive program for monitoring water resources will by necessity use remote sensing data collected by multiple platforms at a range of spatial and temporal scales.

Nonetheless, remote sensing is not without limitations. Chief among these is the infrequent acquisition of the medium to high-resolution imagery needed as input for re- mote sensing-based models to determine ET. This infrequent acquisition of imagery is due to both lengthy return intervals and the presence of cloud cover (Ryu et al., 2012; Van Niel et al., 2012; Cammalleri et al., 2013). To provide temporally continuous ET estimates, the moisture flux during the period between data acquisitions is often estimated using an interpolation technique commonly referred to as temporal upscaling. This well-established approach, which can be applied at either sub-daily or daily time steps, estimates the moisture flux as the product of some reference quantity $(\chi)$ and its associate scaled metric $(f)$ according to

$\widehat{\mathrm{ET}}_{t}=\chi_{t} f_{t}$,

where $\widehat{\mathrm{ET}}$ is the estimated ET and $t$ indicates the time period of the estimate. While it is typically related to the moisture flux, $\chi$ is a quantity that can be measured or estimated more readily than the moisture flux itself. The scaled metric is the ratio between $\chi$ and the moisture flux. For example, it is quite common to estimate ET expressed in terms of the latent heat flux $(\lambda E)$ using the available energy $(A)$, here defined as the net radiation less the soil heat flux, as the reference quantity, and evaporative fraction $\left(f_{A}\right)$ as the scaled metric (e.g., Crago and Brutsaert, 1996; Bastiaanssen et al., 1998; Suleiman and Crago, 2004; Colaizzi et al., 2006; Hoedjes et al., 2008; Van Niel et al., 2011; Delogu et al., 2012).

For the periods between data retrievals, $f$ is estimated via interpolation. As a result, this approach is predicated on the assumption that $f$ is self-preserving, i.e., that it is constant or nearly constant, and thus varies only slowly over time (Brutsaert and Sugita, 1992; Nichols and Cuenca, 1993; Crago, 1996). In order to conform to this assumption, the components of the radiation or energy budget are often selected as $\chi$ such that $f$ is an analog of evaporative fraction. Examples of these quantities include the incident solar radiation ( $K \downarrow$ Jackson et al., 1983; Zhang and Lemeur, 1995) or extraterrestrial solar radiation ( $K \downarrow_{\mathrm{TOA}}$; Ryu et al., 2012). However, a number of recent studies indicate the assumption of selfpreservation is only approximate for these quantities. For example, both Gentine et al. (2007) and Hoedjes et al. (2008) showed that the self-preservation of evaporative fraction is sensitive to soil moisture conditions and fractional vegetation cover. Similarly, Lhomme and Elguero (1999) and later Van Niel et al. (2012) showed that the degree of self-preservation can be influenced by cloud cover. As such, the assumption of clear-sky conditions is a significant potential source of error in the ET estimates that must be considered when utilizing or evaluating temporally upscaled moisture flux data (Van Niel et al., 2012; Peng et al., 2013; Cammalleri et al., 2014). Other studies have focused on using a quantity derived from the local meteorological conditions as $\chi$ because it would consider many of the meteorological factors that influence the moisture flux. For example, Tasumi et al. (2005) proposed using the reference ET for alfalfa $\left(\mathrm{ET}_{\mathrm{r}}\right)$ as $\chi$; later, Allen et al. (2007) proposed using the standardized reference evapotranspiration $\left(\mathrm{ET}_{0}\right)$ as $\chi$. In both cases, the resulting $f$ 
is equivalent to a crop coefficient and would share its characteristics. As a result, $f$ derived from $\mathrm{ET}_{\mathrm{r}}$ or $\mathrm{ET}_{0}$ can be treated in much the same fashion as a crop coefficient and is assumed to be nearly constant, changing only slowly with time (Colaizzi et al., 2006; Chavez et al., 2008).

By assessing the error introduced into ET estimates by temporal upscaling under realistic conditions, this study sought to achieve two goals: (i) to provide insights into the relative strengths of the differing temporal upscaling approaches, and (ii) to determine the maximum return interval threshold for obtaining acceptable estimates of daily ET. Specifically, this study uses in situ measurements collected over a variety of land cover types as a proxy for remotely sensed data to evaluate the impact of multiple reference quantities and interpolation techniques, and to revisit intervals on the estimated daily moisture flux. The study focuses on daytime mean data to evaluate temporal upscaling at a daily time step. It also assumes perfect retrieval of the flux; in other words, no error was introduced into ET data to approximate the error or uncertainty in the estimates of ET from the remote sensing-based models. Since any errors in the remote sensing-based ET estimates propagate into the calculation of $f$ and the subsequent temporal upscaling, this analysis represents the best-case scenario. The following section provides an overview of the field measurements along with the reference quantities, interpolation techniques, and evaluation methods used in this study. Section 3 provides a discussion of the results of this study, while the final section encapsulates the conclusions that can be drawn from those results.

\section{Methods}

\subsection{Datasets}

Data, including local meteorological conditions (wind speed and direction, air temperature, humidity, atmospheric pressure, and precipitation), radiation budget (incident and reflected solar radiation, incident and terrestrial longwave radiation, and net radiation), surface fluxes (sensible, latent, and soil heat fluxes), and surface conditions, collected at numerous sites within the Ameriflux network (Baldocchi et al., 2001), were used for this study. Specifically, the data were collected at 20 Ameriflux sites (Figs. 1 and 2; Table 1) distributed across the contiguous United States and representing four distinct land cover types. These are (i) croplands (maize (Zea mays)/soy (Glycine max) rotation); (ii) grasslands; (iii) forests (evergreen needleleaf and broadleaf deciduous); and (iv) open-canopy (shrubland and woody savanna). Measurements were collected for a minimum of 5 years at each of the sites selected. Further information regarding the field sites, measurement procedures, and postprocessing protocols for Ameriflux is presented in Baldocchi et al. (2001); the data are archived at the Oak Ridge National Laboratory and are available at http://ameriflux.ornl.gov/.

After forcing closure of the energy balance while maintaining a constant Bowen ratio (Twine et al., 2000) in order to more closely match the characteristics of the output from the models, the $30 \mathrm{~min}$ measurements were used to calculate the various $\chi$ and $f$. Finally, the daytime mean of the fluxes and other necessary quantities were calculated for use in the subsequent analyses. Although it can be taken nominally as the period between 08:00 and 18:00 LST, daytime is defined herein as the period between the first and last measurements during a given day when the incident solar radiation exceeded $100 \mathrm{~W} \mathrm{~m}^{-2}$.

\subsection{Reference quantities and scaled metrics}

The first of the $\chi$ derived from meteorological data, $\lambda E_{0}$, is derived from $\mathrm{ET}_{0}$, which is described by Allen et al. (1998) as the hypothetical ET (or $\lambda E$ ) from a well-watered grass surface with an assumed height of $0.12 \mathrm{~m}$ and albedo of 0.23 . It is calculated using a simplified form of the PenmanMonteith equation. For this study, the updated relationship given by Walter et al. (2005) was used:

$\mathrm{ET}_{0}=\frac{0.408 \Delta\left(R_{\mathrm{n}}-G\right)+\gamma \frac{C_{\mathrm{n}}}{(T+273)} U\left(e_{\mathrm{s}}-e_{\mathrm{a}}\right)}{\Delta+\gamma\left(1+U C_{d}\right)}$,

where $\Delta$ is the slope of the saturation vapor pressuretemperature curve $\left(\mathrm{kPa} \mathrm{K}^{-1}\right), R_{\mathrm{n}}$ is the net radiation $\left(\mathrm{W} \mathrm{m}^{-2}\right), G$ is the soil heat flux $\left(\mathrm{W} \mathrm{m}^{-2}\right), \gamma$ is the psychrometric constant $\left(\mathrm{kPa} \mathrm{K}^{-1}\right), C_{\mathrm{n}}$ is a constant $\left(37^{\circ} \mathrm{C} \mathrm{s}^{2} \mathrm{~m}^{-2}\right)$, $T$ is the air temperature $\left({ }^{\circ} \mathrm{C}\right), U$ is the wind speed $\left(\mathrm{m} \mathrm{s}^{-1}\right)$, $e_{\mathrm{S}}$ is the saturation water vapor pressure $(\mathrm{kPa}), e_{\mathrm{a}}$ is the actual water vapor pressure $(\mathrm{kPa})$, and $C_{d}$ is a constant $\left(0.24 \mathrm{~s} \mathrm{~m}^{-1}\right)$. This relationship is nearly identical to the one given in Allen et al. (1998); the two formulae differ only with regard to the assumed surface resistance. While the surface resistance is assumed to be $70 \mathrm{~s} \mathrm{~m}^{-1}$ by Allen et al. (1998), it is assumed to be $50 \mathrm{~s} \mathrm{~m}^{-1}$ in the later work. While modest, this modification yields improved results when the daytime moisture flux is calculated on an hourly basis (Walter et al., 2005). The result is converted to $\lambda E_{0}$ by multiplying by the product of the density of water and the latent heat of vaporization. Similarly, $\lambda E_{\mathrm{eq}}$, which can be thought of as the energy-driven moisture flux that is independent of surface resistance, can be expressed according to

$\lambda E_{\text {eq }}=A \frac{\Delta}{\Delta+\gamma}$

with the variables defined as above (McNaughton, 1976; Raupach, 2001).

\subsection{Interpolation techniques}

In addition to piecewise linear interpolation, two piecewise spline interpolation methods were evaluated as a part of this 


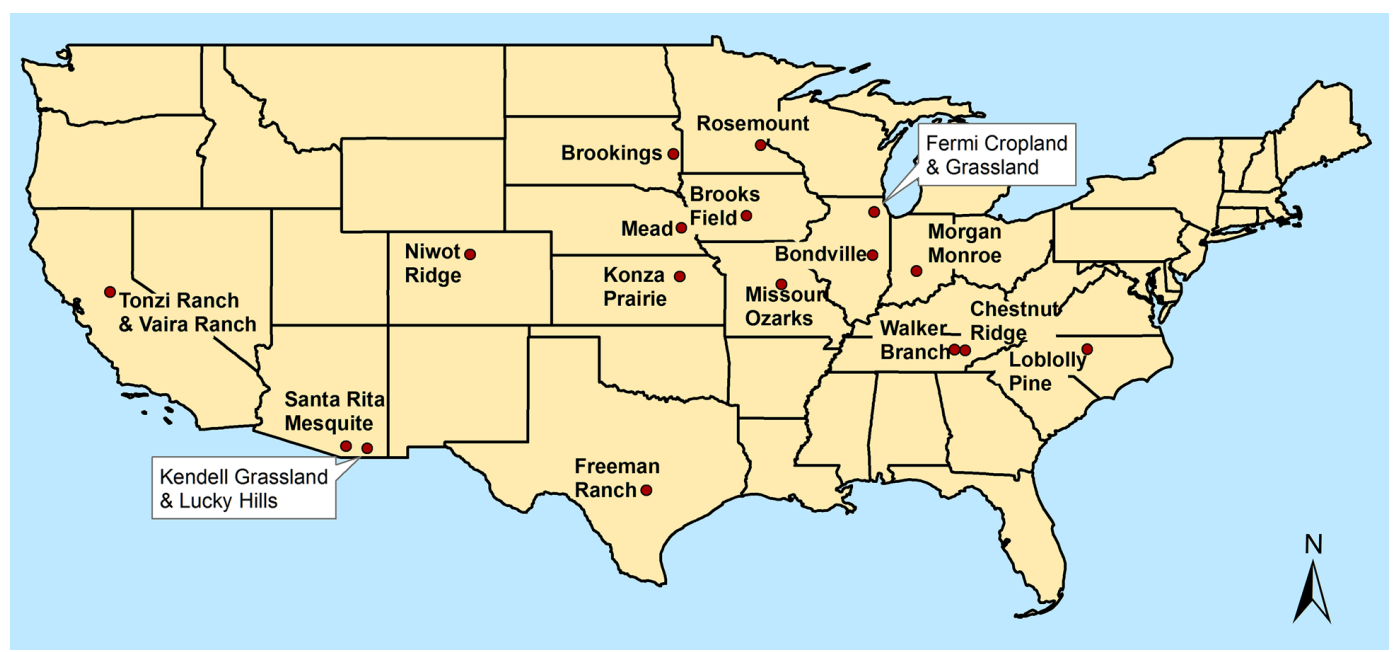

Figure 1. Map showing the location of the Ameriflux sites used in this study.

Table 1. Summary of Ameriflux sites used in this study.

\begin{tabular}{|c|c|c|c|c|c|c|c|c|c|c|c|}
\hline Site & Location & $\begin{array}{l}\text { Land } \\
\text { cover }\end{array}$ & $\begin{array}{l}\text { Mean } \\
\text { annual } \\
\text { temp. }\end{array}$ & $\begin{array}{l}\text { Mean } \\
\text { annual } \\
\text { rainfall }\end{array}$ & $\begin{array}{l}\text { Study } \\
\text { period }\end{array}$ & Site & Location & $\begin{array}{l}\text { Land } \\
\text { cover }\end{array}$ & $\begin{array}{l}\text { Mean } \\
\text { annual } \\
\text { temp. }\end{array}$ & $\begin{array}{l}\text { Mean } \\
\text { annual } \\
\text { rainfall }\end{array}$ & $\begin{array}{l}\text { Study } \\
\text { period }\end{array}$ \\
\hline Bondville & $\begin{array}{l}40.006^{\circ} \mathrm{N} \\
88.290^{\circ} \mathrm{W}\end{array}$ & $\begin{array}{l}\text { Cropland } \\
\text { (maize/soy) }\end{array}$ & $11.0^{\circ} \mathrm{C}$ & $991 \mathrm{~mm}$ & $2000-2008$ & $\begin{array}{l}\text { Lucky } \\
\text { Hills }\end{array}$ & $\begin{array}{l}31.744^{\circ} \mathrm{N} \\
110.052^{\circ} \mathrm{W}\end{array}$ & Shrubland & $17.6^{\circ} \mathrm{C}$ & $320 \mathrm{~mm}$ & $2007-2012$ \\
\hline Brookings & $\begin{array}{l}44.345^{\circ} \mathrm{N} \\
96.836^{\circ} \mathrm{W}\end{array}$ & $\begin{array}{l}\text { Woody } \\
\text { savanna }\end{array}$ & $6.0^{\circ} \mathrm{C}$ & $586 \mathrm{~mm}$ & 2004-2010 & Mead & $\begin{array}{l}41.165^{\circ} \mathrm{N} \\
96.477^{\circ} \mathrm{W}\end{array}$ & $\begin{array}{l}\text { Cropland } \\
\text { (maize) }\end{array}$ & $10.1^{\circ} \mathrm{C}$ & $789 \mathrm{~mm}$ & 2001-2012 \\
\hline Brooks Field & $\begin{array}{l}41.692^{\circ} \mathrm{N} \\
93.691^{\circ} \mathrm{W}\end{array}$ & Cropland & $8.9^{\circ} \mathrm{C}$ & $847 \mathrm{~mm}$ & $2005-2011$ & $\begin{array}{l}\text { Morgan } \\
\text { Monroe }\end{array}$ & $\begin{array}{l}39.323^{\circ} \mathrm{N} \\
86.413^{\circ} \mathrm{W}\end{array}$ & $\begin{array}{l}\text { Broadleaf } \\
\text { deciduous } \\
\text { forest }\end{array}$ & $10.9^{\circ} \mathrm{C}$ & $1032 \mathrm{~mm}$ & 2004-2014 \\
\hline Chestnut Ridge & $\begin{array}{l}35.931^{\circ} \mathrm{N} \\
84.332^{\circ} \mathrm{W}\end{array}$ & $\begin{array}{l}\text { Broadleaf } \\
\text { deciduous } \\
\text { forest }\end{array}$ & $13.9^{\circ} \mathrm{C}$ & $1359 \mathrm{~mm}$ & $2005-2010$ & $\begin{array}{l}\text { Niwot } \\
\text { Ridge }\end{array}$ & $\begin{array}{l}40.033^{\circ} \mathrm{N} \\
105.546^{\circ} \mathrm{W}\end{array}$ & $\begin{array}{l}\text { Evergreen } \\
\text { needleleaf } \\
\text { forest }\end{array}$ & $1.5^{\circ} \mathrm{C}$ & $800 \mathrm{~mm}$ & 2001-2012 \\
\hline Fermi Cropland & $\begin{array}{l}41.859^{\circ} \mathrm{N} \\
88.223^{\circ} \mathrm{W}\end{array}$ & $\begin{array}{l}\text { Cropland } \\
\text { (maize/soy) }\end{array}$ & $9.2^{\circ} \mathrm{C}$ & $929 \mathrm{~mm}$ & 2005-2011 & $\begin{array}{l}\text { Missouri } \\
\text { Ozarks }\end{array}$ & $\begin{array}{l}38.744^{\circ} \mathrm{N} \\
-92.200^{\circ} \mathrm{W}\end{array}$ & $\begin{array}{l}\text { Broadleaf } \\
\text { deciduous } \\
\text { forest }\end{array}$ & $12.1^{\circ} \mathrm{C}$ & $986 \mathrm{~mm}$ & 2004-2013 \\
\hline Fermi Grassland & $\begin{array}{l}41.841^{\circ} \mathrm{N} \\
88.241^{\circ} \mathrm{W}\end{array}$ & Grassland & $9.2^{\circ} \mathrm{C}$ & $929 \mathrm{~mm}$ & $2005-2011$ & Rosemount & $\begin{array}{l}44.714^{\circ} \mathrm{N} \\
93.090^{\circ} \mathrm{W}\end{array}$ & $\begin{array}{l}\text { Cropland } \\
\text { (maize/soy) }\end{array}$ & $6.4^{\circ} \mathrm{C}$ & $879 \mathrm{~mm}$ & 2004-2012 \\
\hline Freeman Ranch & $\begin{array}{l}29.940^{\circ} \mathrm{N} \\
-97.990^{\circ} \mathrm{W}\end{array}$ & Woody savanna & $19.5^{\circ} \mathrm{C}$ & $864 \mathrm{~mm}$ & $2005-2009$ & $\begin{array}{l}\text { Santa Rita } \\
\text { Mesquite }\end{array}$ & $\begin{array}{l}31.821^{\circ} \mathrm{N} \\
110.866^{\circ} \mathrm{W}\end{array}$ & $\begin{array}{l}\text { Woody } \\
\text { savanna }\end{array}$ & $17.9^{\circ} \mathrm{C}$ & $380 \mathrm{~mm}$ & 2004-2012 \\
\hline Kendall Grassland & $\begin{array}{l}31.737^{\circ} \mathrm{N} \\
109.942^{\circ} \mathrm{W}\end{array}$ & Grassland & $15.6^{\circ} \mathrm{C}$ & $407 \mathrm{~mm}$ & 2004-2012 & $\begin{array}{l}\text { Tonzi } \\
\text { Ranch }\end{array}$ & $\begin{array}{l}38.432^{\circ} \mathrm{N} \\
120.966^{\circ} \mathrm{W}\end{array}$ & $\begin{array}{l}\text { Woody } \\
\text { savanna }\end{array}$ & $15.8^{\circ} \mathrm{C}$ & $559 \mathrm{~mm}$ & 2001-2012 \\
\hline Konza Prairie & $\begin{array}{l}39.082^{\circ} \mathrm{N} \\
96.560^{\circ} \mathrm{W}\end{array}$ & Grassland & $12.8^{\circ} \mathrm{C}$ & $867 \mathrm{~mm}$ & $2006-2012$ & $\begin{array}{l}\text { Vaira } \\
\text { Ranch }\end{array}$ & $\begin{array}{l}38.407^{\circ} \mathrm{N} \\
120.910^{\circ} \mathrm{W}\end{array}$ & Grassland & $15.8^{\circ} \mathrm{C}$ & $559 \mathrm{~mm}$ & 2001-2012 \\
\hline Loblolly pine & $\begin{array}{l}35.978^{\circ} \mathrm{N} \\
79.094^{\circ} \mathrm{W}\end{array}$ & $\begin{array}{l}\text { Evergreen needleleaf } \\
\text { forest }\end{array}$ & $14.4^{\circ} \mathrm{C}$ & $1170 \mathrm{~mm}$ & $2001-2008$ & Walker Branch & $\begin{array}{l}35.959^{\circ} \mathrm{N} \\
84.787^{\circ} \mathrm{W}\end{array}$ & $\begin{array}{l}\text { Broadleaf } \\
\text { deciduous } \\
\text { forest }\end{array}$ & $13.7^{\circ} \mathrm{C}$ & $1372 \mathrm{~mm}$ & 2001-2007 \\
\hline
\end{tabular}

study, namely cubic and Hermite spline interpolation. In contrast to linear interpolation, which tends to yield accurate results only when the underlying data vary smoothly over time, the splining methods are less prone to error when the observed data change abruptly (Trefethen, 2013). Similarly, the more computationally complex Hermite spline method typically yields more accurate results when the gaps between observed data points are large (De Boor, 1994).

As the name implies, the piecewise linear interpolation estimates $f$ using a family of $n-1$ linear relationships defined such that the linearly interpolated $f\left(\hat{f}_{L}\right)$ at time $t$ is deter- mined according to

$\hat{f}_{L_{i}}(t)=f_{i}+\left(t_{i+1}-t_{i}\right) m_{i} h$,

where $n$ is the number of observed data points, $f_{i}$ is the known $f$ at time $t_{i}, m_{i}$ is the slope of a straight line relationship for the period between $t_{i}$ and $t_{i+1}$ defined as $m_{i}=\left(f_{i+1}-f_{i}\right) /\left(t_{i+1}-t_{i}\right)$, and $h$ is the time normalized between 0 and 1 and is defined as $h=\left(t-t_{i}\right) /\left(t_{i+1}-t_{i}\right)$. The piecewise cubic spline interpolation function is a family of $n-1$ cubic polynomials defined such that the interpolated 


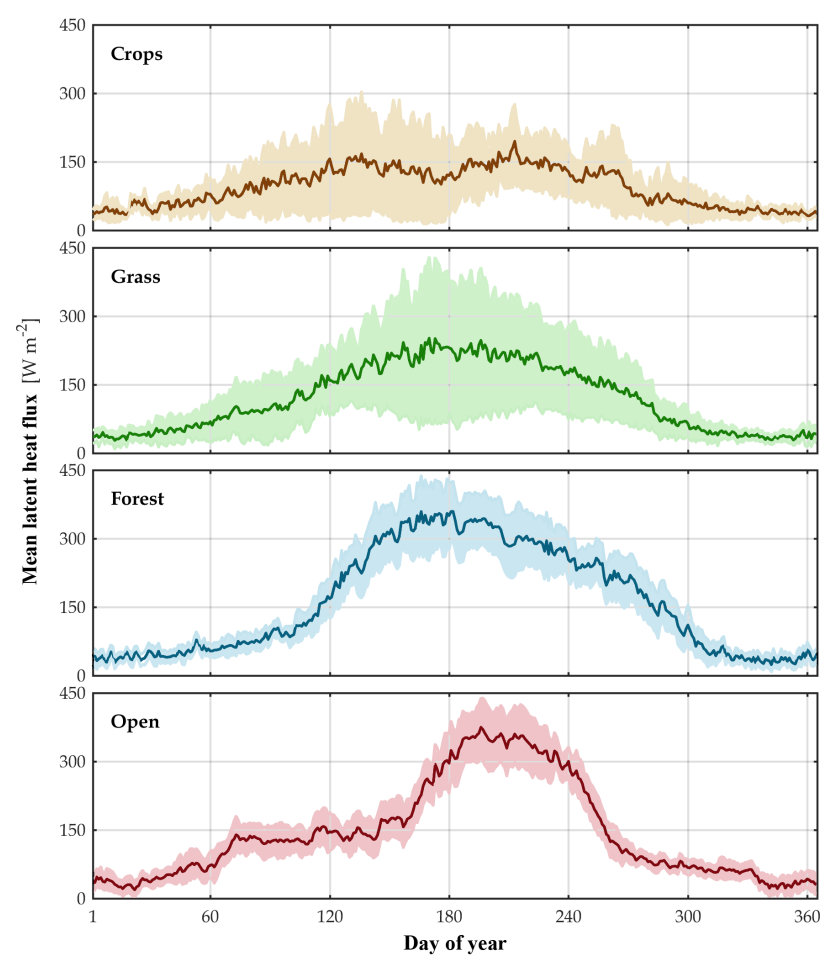

Figure 2. The mean daytime latent heat flux is shown for each of the land cover types. The mean flux was calculated using the daytime mean flux data for all of the years considered at each site. The shaded area represents 1 standard deviation about the mean.

$f\left(\hat{f}_{S}\right)$ at time $t$ is determined according to

$$
\begin{aligned}
\hat{f}_{S_{i}}(t) & =f_{i}+a_{i}\left[\left(t_{i+1}-t_{i}\right) h\right]^{3}+b_{i}\left[\left(t_{i+1}-t_{i}\right) h\right]^{2} \\
& +c_{i}\left[\left(t_{i+1}-t_{i}\right) h\right],
\end{aligned}
$$

where the coefficients $a_{i}, b_{i}$, and $c_{i}$ are determined by simultaneously solving the series of $n-1$ equations with the constraints that the interpolation function, as well as its first and second derivatives, must be continuous and pass exactly through the known values of $f$. Similarly, the final interpolation technique, piecewise Hermite cubic spline, defines the

$$
\begin{aligned}
\hat{f}_{H_{i}}(t) & \left.=2 h^{3}-3 h^{2}+1\right) f_{i}+\left(-2 h^{3}-3 h^{2}\right) f_{i+1} \\
& +\cdots h\left(h^{2}-2 h+1\right)\left(t_{i+1}-t_{i}\right) S_{i} \\
& +h\left(h^{2}-h\right)\left(t_{i+1}-t_{i}\right) S_{i+1},
\end{aligned}
$$

where $S_{i}$ is the slope of the curve at time $t_{i}$ (De Boor, 1994). For this study, it is calculated according to

$S_{i}=\frac{1}{2}\left(\frac{f_{i+1}-f_{i}}{t_{i+1}-t_{i}}+\frac{f_{i}-f_{i-1}}{t_{i}-t_{i-1}}\right)$

and the variables are defined as above (Moler, 2004).

For this analysis, temporal upscaling was conducted at each of the Ameriflux sites using all possible combinations of $f$ and interpolation methods. Specifically, it was conducted with data representing return intervals of up to 32 days generated from the daytime mean data at each site. In order to maximize the robustness of the statistical analysis, all possible realizations - the unique yet equivalent time series that can be generated from the data collected at a particular site while maintaining a constant return interval - were considered in the analysis. The total number of possible realizations for a given return interval is equal to the length of the return interval. The individual realizations were generated by beginning the time series on consecutive days.

Again, to emulate the temporal upscaling of flux data derived from remotely sensed data as closely as possible, efforts were made to ensure that the observations used for the interpolation were collected on clear-sky days. Clear-sky days were identified as those where the daytime mean of the measured $K \downarrow$ was within $25 \%$ of the predicted value from a simple radiation model; this threshold was selected based on a preliminary analyses comparing the model results with observations on known clear-sky days. The incident solar radiation was estimated as the product of $K \downarrow_{\text {TOA }}$ calculated following Meeus et al. (1991) and atmospheric transmissivity calculated according to Brutsaert (1975). In order to ensure a constant return interval for a given interpolation, if a day was judged to be cloudy, both the observed flux on that day and the estimated flux for those subsequent days derived from it were omitted from the statistical analysis. Although the number of days flagged due to cloudy conditions and omitted from subsequent analyses varied depending on the site and the return interval being modeled, at least 1200 days were considered for each of the analyses at each site.

\subsection{Statistical metrics}

As discussed by Wilks (2006), persistence, i.e., the degree of self-preservation, can be assessed via autocorrelation $(\rho)$. For a given lag $(h)$, i.e., the offset between measurement pairs, the autocorrelation is defined according to

$\rho=\frac{\sum_{i=1}^{n-h}\left[\left(x_{i}-\bar{x}_{-}\right)\left(x_{i+h}-\bar{x}_{+}\right)\right]}{\sqrt{\sum_{i=1}^{n-h}\left(x_{i}-\bar{x}_{-}\right)^{2} \sum_{i=1}^{n-h}\left(x_{i+h}-\bar{x}_{+}\right)^{2}}}$,

where $n$ is the number of data points, $\bar{x}_{-}$is the mean of the first $m$ data points and $\bar{x}_{+}$is the mean of the final $m$ data points; $m$ is defined as the total number of data points less the length of the lag, i.e., $m=n-h$.

A pair of statistics are used to evaluate the accuracy of the temporal upscaling. The first of these is the root mean square error (RMSE):

$\mathrm{RMSE}=\sqrt{\frac{1}{n} \sum_{i=1}^{n}\left(x_{i}-\hat{x}_{i}\right)^{2}}$,

where $n$ is the number of data points, $x$ is the observed flux, and $\hat{x}$ is the flux predicted by temporal upscaling. However, because the squared difference term in the RMSE tends to 



Lag [days]

Figure 3. The representative autocorrelation function derived for each land cover type and scaled metric used in this study is shown. The shaded area represents 1 standard deviation about the mean.

overemphasize the effects of large errors (Legates and McCabe, 1999; Willmott and Matsuura, 2005; Willmott et al., 2012), the mean absolute error (MAE) was also calculated as follows:

$\operatorname{MAE}=\frac{1}{n} \sum_{i=1}^{n}\left|x_{i}-\hat{x}_{i}\right|$,

with the variables defined as above.

Once calculated for the individual sites, the statistics were aggregated to represent the typical results for a given land cover type. The aggregation was accomplished by calculating the arithmetic means after conducting any necessary trans- form. For example, both the autocorrelation and the RMSE are non-additive quantities that cannot be averaged directly; instead, they must first be transformed into an additive quantity. In the case of the former, the autocorrelation was aggregated by averaging the results for the individual analysis periods at each of the sites after applying a Fisher $z$ transformation (Burt and Barber, 1996). Similarly, the RMSE data were averaged after first transforming them to the mean square error. 


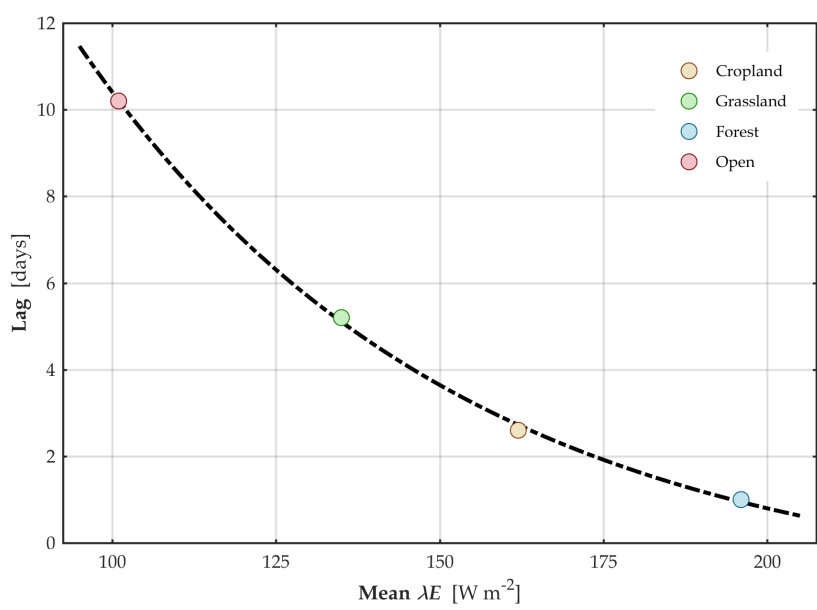

Figure 4. The maximum lag where the autocorrelation function exceeds 0.50 plotted as a function of the mean daytime latent heat flux is shown.

\section{Results and discussion}

\subsection{Persistence of scaled quantities}

Due to its importance in determining the accuracy of the estimates, the persistence or degree of self-preservation exhibited by the various $f$ used in this study was evaluated by determining its autocorrelation function. For each site, the autocorrelation was calculated for each contiguous segment of daytime mean data that was at least 48 days in length (1.5 times the maximum return interval considered herein).

As can be seen in Fig. 3, which shows the mean autocorrelation function for each $f$ and land cover type, all $f$ performed similarly. In all cases, $\rho$ decreased in inverse proportion to $h$, dropping to less than 0.50 within 3 to 10 days. Also, for any given land cover, the mean autocorrelation functions for the analogs of evaporative fraction, namely $f_{K \downarrow}$, $f_{R_{\mathrm{n}}}$, and $f_{A}$, were statistically indistinguishable from one another based on $t$ tests conducted at the $95 \%$ confidence level. Similarly, no statistically significant difference between the mean autocorrelation functions of $f_{\lambda E_{0}}$ and $f_{\lambda E_{\mathrm{eq}}}$ was found. Nonetheless, there were statistically significant, albeit modest, differences between the autocorrelation functions associated with $f$ derived from evaporative fraction analogs and those derived from meteorological data. Regardless of land cover, $\rho$ associated with $f_{K \downarrow}, f_{R_{\mathrm{n}}}$, and $f_{A}$ tended to be greater than $\rho$ associated with either $f_{\lambda E_{0}}$ or $f_{\lambda E_{\mathrm{eq}}}$. On average, the difference was approximately 0.03 .

The results of this analysis, which are consistent with results of other studies (Farah et al., 2004; Lu et al., 2013) that found significant day-to-day and seasonal variations in evaporative fraction, indicate that the long-term persistence of $f$ is very limited. This result also suggests that interpolated values of $f$ may not accurately reflect the actual values and, as a result, may be a key source of error when using temporal upscaling to estimate the moisture flux between image retrievals.

The figure also shows there was significant variability from site to site within a given land cover type, particularly for longer lags. Although the specific causes of these differences are not fully understood, there are a number of factors that likely contribute. For example, there are difference in both species composition and climate at the various sites. Consider, as an example, the forest class which includes both coniferous and broadleaf deciduous forest. Moreover, the species composition varies even among sites of the same forest type; for example, the dominant species at the Niwot Ridge site are subalpine fir (Abies lasiocarpa) and Engelmann spruce (Picea engelmannii) while, as the name implies, the dominant species at the Loblolly Pine site is loblolly pine (Pinus taeda). At the same time, the mean annual temperature at the forested sites ranged from 1.5 to $14.4^{\circ} \mathrm{C}$, while the mean annual precipitation varied from 800 to $1372 \mathrm{~mm}$. Similarly the mean annual temperature and precipitation at the cropland sites, which are all planted on a rotation of maize and soy, range between 6.4 and $11.0^{\circ} \mathrm{C}$ and 789 and $991 \mathrm{~mm}$, respectively.

Further analysis shows differences in the mean autocorrelation functions exist between land cover types. Regardless of the scaled quantity considered, the mean autocorrelation function decreases most rapidly over forested sites and most slowly over the open sites. Indeed, if the lag where the mean autocorrelation function reaches some threshold value, e.g., 0.50 , plotted as a function of the mean daytime latent heat flux (Fig. 4), it can be seen that persistence decreases exponentially with the increasing moisture flux. While the underlying cause of this relationship is unclear, it suggests the return interval necessary to achieve accurate estimates of ET via temporal upscaling will be longer over relatively dry regions with a low moisture flux than over regions where ET is high.

\subsection{Accuracy of the interpolated scaled quantities}

Both the RMSE and MAE of the interpolated estimates of each $f$ were calculated for all land cover types and return intervals up to 32 days. As can be seen in Figs. 5 and 6, both metrics behaved similarly; regardless of the land cover type, scaled quantity, or interpolation method considered, the error increased rapidly with increasing return interval until a plateau was reached. In all cases, the RMSE, which increased according to a logarithmic function of the return interval, reached $75 \%$ of its peak value within 5 days. For comparison, the mean maximum RMSE for each land cover type was $0.26,0.21,0.28$, and 0.17 for croplands, grasslands, forest, and open canopies, respectively. Although it also increased logarithmically, the amount of time needed for the MAE to reach $75 \%$ of the peak value was more variable, ranging between 5 and 10 days. Again, for purposes of comparison, the mean maximum MAE was $0.22,0.14,0.16$, and 




Figure 5. The root mean square error (RMSE) of the estimates of the scaled quantities is shown for each land cover type and interpolation scheme.

0.10 , respectively, for croplands, grasslands, forest, and open canopies. Further, the MAE increased most rapidly for those land cover types that exhibited the highest moisture flux. The largest error, whether measured in terms of RMSE or MAE, also tended to be associated with the forest and cropland sites where the mean ET was largest.

The results also show that all of the interpolation methods yielded similar results for short return intervals of less than 8 days. In contrast, for longer return intervals, both the RMSE and MAE of the estimates using the spline interpolation methods were greater than when linear interpolation is used (Figs. 5 and 6). Moreover, the error of the estimates tended to be much noisier for the spline techniques, partic- ularly the cubic spline method, which exhibited periods of very large errors. These large noisy errors, which are most evident in the RMSE - perhaps because it is more sensitive to outliers than the MAE - are indicative of "overshoot" errors by the spline interpolation. The large errors are also most pronounced for those land cover types that also demonstrated the highest average ET and the lowest autocorrelation.

\subsection{Accuracy of the latent heat flux estimates}

Not unexpectedly, the accuracy of the moisture fluxes estimated via temporal upscaling closely mirrors the accuracy of the interpolated $f$. As was the case with $f$, both the RMSE and the MAE of the flux estimates increase rapidly with re- 

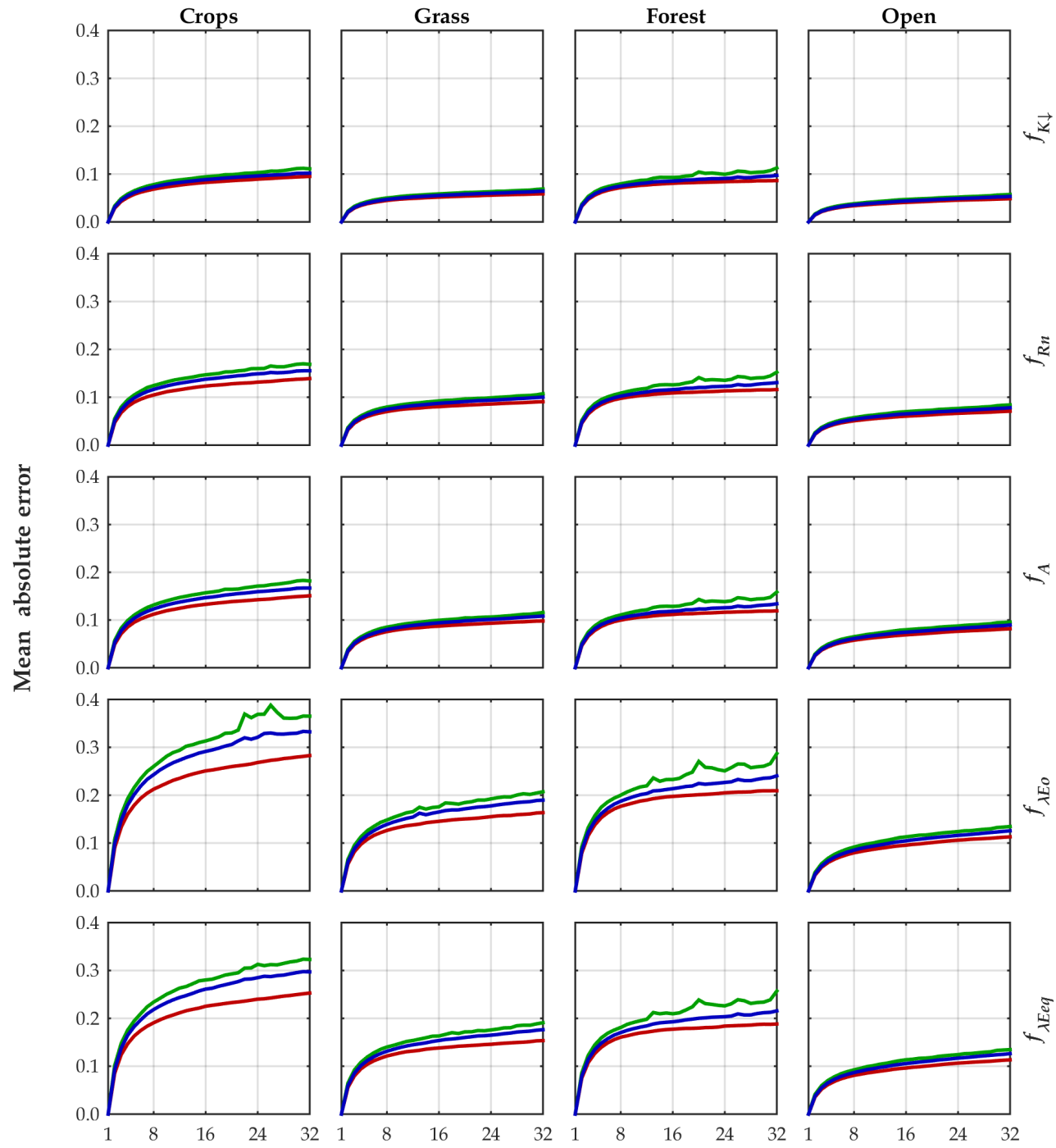

Return interval [days]

Linear $\longrightarrow$ Cubic spline $\longrightarrow$ Hermite spline

Figure 6. The mean absolute error (MAE) of the estimates of the scaled quantities is shown for each land cover type and interpolation scheme.

turn interval to a maximum value following a logarithmic function (Figs. 7 and 8). In the case of the RMSE, the maximum error ranged between 31 and $66 \mathrm{~W} \mathrm{~m}^{-2}$. In the case of the MAE, it ranged between 22 and $54 \mathrm{~W} \mathrm{~m}^{-2}$. Again, the greatest error is associated with the land cover with the highest ET, i.e., forest and cropland.

These plots, like those for $f$, show little difference among the interpolation techniques when the return interval is short. For return intervals longer than about 8 days, however, the spline interpolation techniques, and especially the cubic spline method, can introduce large errors into the flux estimates due to the "overshoot" errors in the interpolation of $f$. These large noisy errors are most evident in the RMSE of forested sites (Fig. 8), but may also be seen to a lesser extent at the cropland sites. Overall, this suggests there is no substantive advantage to using the more computational complex spline techniques over linear regression; rather, the propensity of spline methods to introduce large errors due to interpolation "overshoot" indicates these techniques should be avoided.

The accuracy, and thus utility, of the various $f$ was evaluated while focusing specifically on the results when linear interpolation was used. Regardless of $f$, an intercomparison of the estimated fluxes using $t$ tests conducted at the $95 \%$ confidence level indicated there was no statistically significant difference in either the flux estimates or the error due to tem- 

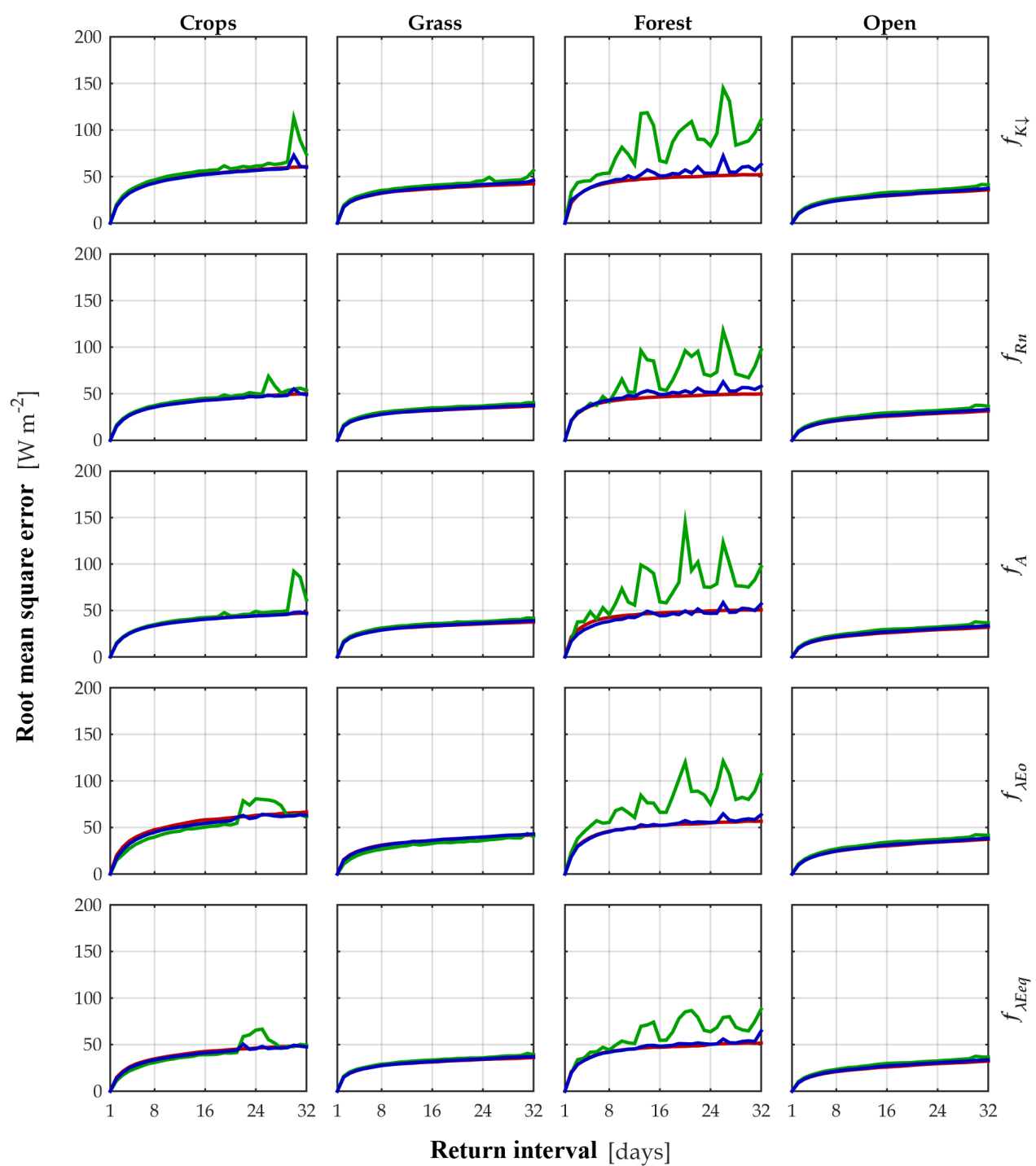

Return interval [days]

Linear Cubic spline Hermite spline

Figure 7. The root mean square error (RMSE) of the latent heat flux derived from each of the scaled quantities is shown for each land cover type and interpolation scheme.

poral upscaling when the return interval was less than 8 days. For longer return intervals, analyses using RMSE (Fig. 9) and MAE (not shown), which yielded similar results, indicated that the error due to temporal upscaling was very similar when $f_{R_{\mathrm{n}}}, f_{A}$, or $f_{\lambda E_{\mathrm{eq}}}$ was used. Indeed, the error introduced using any of these three quantities was statistically identical based on $t$ tests conducted at the $95 \%$ confidence level. Moreover, with the exception of the forest sites, where the error due to temporal upscaling using $f_{K \downarrow}$ was the same as the error introduced by using $f_{R_{\mathrm{n}}}, f_{A}$, or $f_{\lambda E_{\mathrm{eq}}}$, temporal upscaling using $f_{R_{\mathrm{n}}}, f_{A}$, and $f_{\lambda E_{\text {eq }}}$ consistently introduced the least error. For a 10-day return interval, as an example, the percent error introduced by these quantities ranges between 21 and $23 \%$, depending on land cover. In contrast, temporal upscaling using $f_{\lambda E_{0}}$ introduced the greatest error. Again, for a 10-day return interval, the percent error associated with $f_{\lambda E_{0}}$ ranges between 24 and $30 \%$, depending on land cover.

\subsection{Estimating optimal return interval thresholds}

Again focusing on the flux estimates when linear interpolation was used, the return interval threshold yielding errors of less than $20 \%$ in the daily ET estimates was identified (Table 2). The $20 \%$ threshold was selected because it is the nominal uncertainty commonly associated with in situ observations such as those collected via eddy covariance. While the return interval associated with the $20 \%$ threshold varied de- 

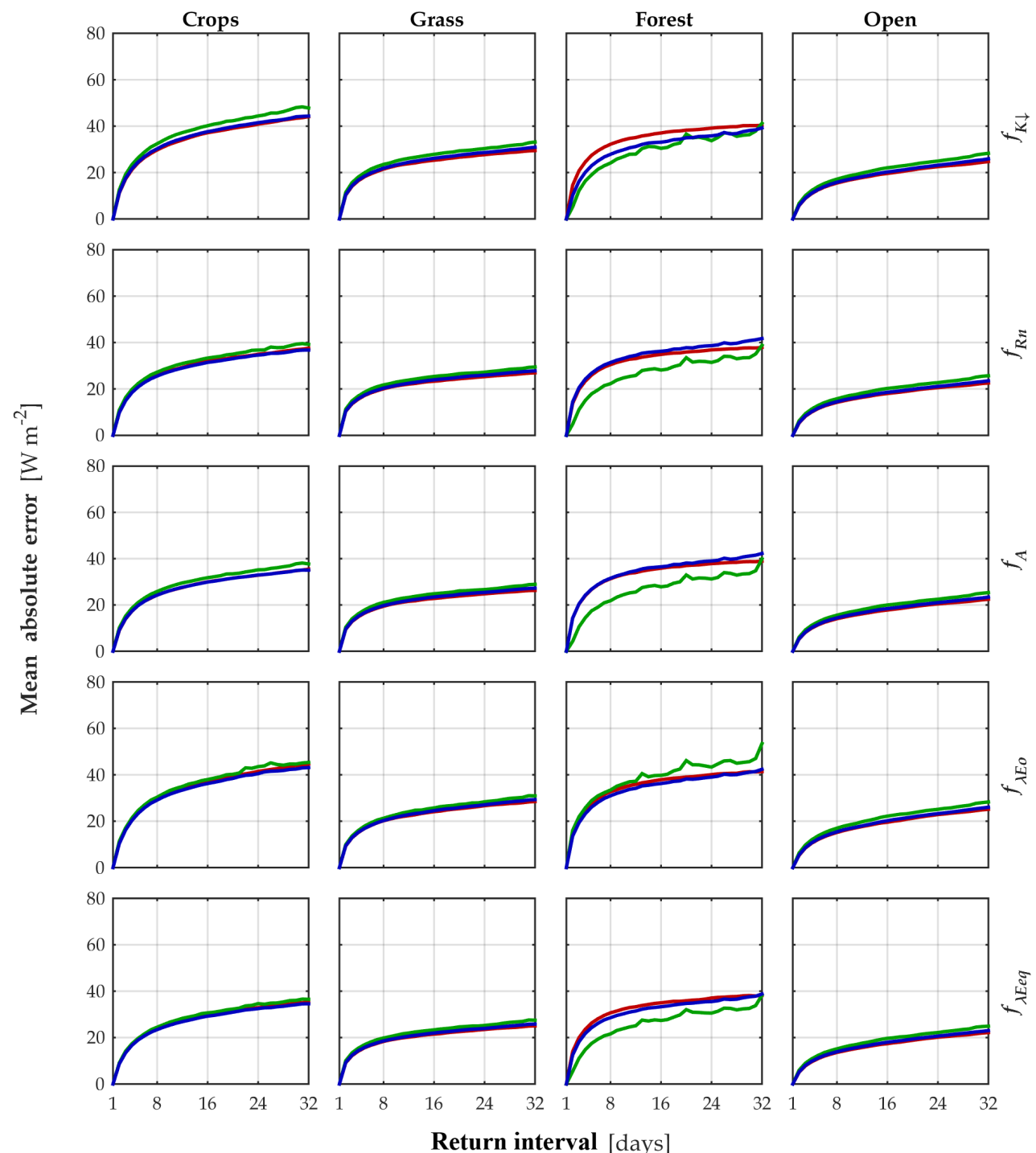

Return interval [days]

$\longrightarrow$ Linear $\longrightarrow$ Cubic Spline $\longrightarrow$ Hermite Spline

Figure 8. The mean absolute error (MAE) of the latent heat flux derived from each of the scaled quantities is shown for each land cover type and interpolation scheme.

pending on land cover type and $f$, the longest return intervals are associated with $f_{\lambda E_{\text {eq }}}$ followed by $f_{R_{\mathrm{n}}}$, and $f_{A}$, which yield statistically identical results, and finally $f_{K \downarrow}$ and $f_{\lambda E_{0}}$, which also yield statistically indistinguishable results based on $t$ tests at the $95 \%$ confidence level. The range of values among the various $f$ was 2 days, on average. This again indicates that the accuracy of temporal upscaling is greatest for $f_{R_{\mathrm{n}}}, f_{A}$, and $f_{\lambda E_{\mathrm{eq}}}$.

By plotting the average threshold return interval for each land cover class against its corresponding mean latent heat flux for that class (Fig. 10), it can be seen that the length of the return interval that will result in no more than $20 \%$ error decreases with the increasing moisture flux. Like $\rho$, the relationship follows an exponential decay function. In this case, however, the curve has a lower bound of 5 days. Based on this, the maximum return interval that can be expected to introduce less than $20 \%$ error to the flux estimates via temporal upscaling for all land cover classes is 5 days. If a threshold of $10 \%$ relative error is used, the threshold falls to only 3 days. Importantly, since the determination of the maximum return interval was made assuming there is no error in the moisture flux used to calculate $f$, they represent the bestcase scenario. In practice, any error in the flux retrieval will propagate into the interpolated flux. As a result the maximum return interval would be somewhat shorter. 
Table 2. The maximum return interval with a relative error of less than $20 \%$ is given for each reference quantity and LULC when linear interpolation was used.

\begin{tabular}{lllcccc}
\hline & \multicolumn{5}{c}{ Reference quantity } \\
\cline { 3 - 6 } & $\begin{array}{c}\text { Incident solar } \\
\text { radiation }\end{array}$ & $\begin{array}{c}\text { Net } \\
\text { radiation }\end{array}$ & $\begin{array}{c}\text { Available } \\
\text { energy }\end{array}$ & $\begin{array}{c}\text { Reference } \\
\text { latent heat } \\
\text { flux }\end{array}$ & $\begin{array}{c}\text { Equilibrium } \\
\text { latent heat } \\
\text { flux }\end{array}$ \\
\hline Land cover & Cropland & 4 & 6 & 7 & 4 & 7 \\
& Grassland & 5 & 7 & 6 & 5 & 8 \\
& Forest & 5 & 6 & 5 & 5 & 6 \\
& Open canopy & 6 & 8 & 8 & 7 & 8 \\
\hline
\end{tabular}
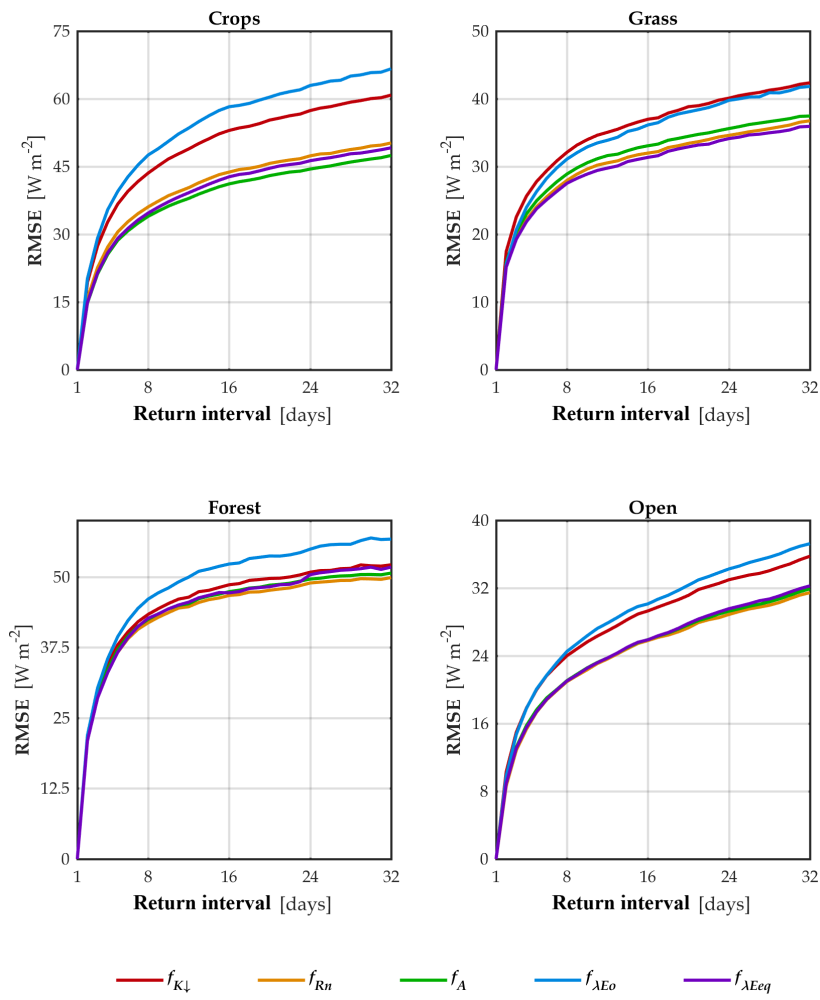

Figure 9. The root mean square error (RMSE) of the latent heat flux derived from each of the scaled quantities is shown for each land cover type when linear interpolation is used.

\section{Conclusions}

The results of this study indicate that the day-to-day persistence of $\chi$ typically used in the temporal upscaling of satellite-based ET retrievals is quite limited. The autocorrelation of daytime means of these quantities decreases to less than 0.5 within 10 days and to less than 0.25 in 7 to 24 days depending on land cover class. More generally, it was found that the number of days for $\rho$ to reach to a given threshold decreases with increasing $\lambda E$ following a well-defined exponential decay function. This suggests that the utility of temporal upscaling is limited to short return intervals, especially

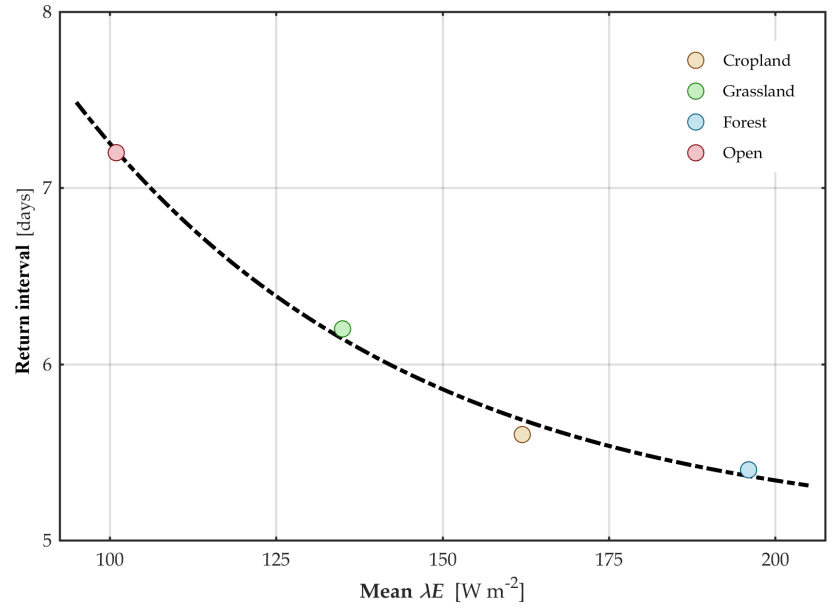

Figure 10. The maximum return interval where the relative error is less than $20 \%$ plotted as a function of the mean daytime latent heat flux.

for land covers such as forest and croplands, which are characterized by large moisture fluxes. The analyses of the RMSE and MAE confirm this inference; in both cases the magnitude of the error increases rapidly with increasing return interval and typically reaches $75 \%$ of the maximum error within 3 to 7 days. Again, the magnitude of the error due to temporal upscaling was greatest over those land cover types with the highest ET. Using $20 \%$ relative error as the threshold, the maximum return interval ranged between 5 and 8 days, on average, depending on land cover type. However, since the maximum return interval decreases to a minimum of 5 days following an exponential decay function of the mean moisture flux, 5 days is the longest return interval that would allow for accurate ET estimates over all land cover types assuming perfect retrieval. While the study found that using $\lambda E_{\mathrm{eq}}, R_{\mathrm{n}}$, or $A$ as $\chi$ tended to produce the most accurate estimates of $\lambda E$ for longer return intervals, for return intervals of 5 days or less, there was no statistically significant difference in the flux estimates. Finally, the comparison of interpolation methods indicated there is no advantage to using the more computationally complex spline interpolation methods. 


\section{Data availability}

The raw micrometeorological datasets used in this study were collected at 20 Ameriflux sites distributed across the contiguous US. The datasets and additional information regarding the Ameriflux network are available at http://ameriflux.ornl.gov/. The datasets specific to each site used here can be obtained as follows: Bondville, http://sites.ameriflux.lbl.gov/US-Bo1/ (Meyers, 1996); Brookings, http://sites.ameriflux.lbl.gov/US-Bkg/ (Meyers, 2004); Brooks Field, http://sites.ameriflux.lbl.gov/US-Br1/ (Prueger and Parkin, 2001); Chestnut Ridge, http://sites.ameriflux.lbl.gov/US-ChR/ (Meyers, 2005); Fermi Cropland, http://sites.ameriflux.lbl.gov/US-IB1/ (Matamala, 2004); Fermi Grassland, http://sites.ameriflux. lbl.gov/US-IB2/ (Matamala, 2005); Freeman Ranch, http://sites.ameriflux.lbl.gov/US-FR2/, (Litvak, 2004); Kendall Grasslands, http://sites.ameriflux.lbl.gov/US-Wkg/, (Scott, 2004b); Konza Prairie, http://sites.ameriflux. lbl.gov/US-Kon/, (Brunsell, 2006); Loblolly Pine, http://sites.ameriflux.lbl.gov/US-Dk3/, (Stoy et al., 2001); Lucky Hills, http://sites.ameriflux.lbl.gov/US-Whs/, (Scott, 2007); Mead, http://sites.ameriflux.lbl.gov/US-NE1/, (Suyker, 2001); Morgan Monroe, http://sites.ameriflux.lbl. gov/US-MMS/, (Novick and Phillips, 1999); Niwot Ridge, http://sites.ameriflux.lbl.gov/US-NR1/, (Blanken, 1998); Missouri Ozarks, http://sites.ameriflux.lbl.gov/US-Moz/, (Wood and Lainhong, 2004); Rosemount, http://sites. ameriflux.lbl.gov/US-Ro1/, (Baker and Griffis, 2002); Santa Rita Mesquite, http://sites.ameriflux.lbl.gov/US-SRM/, (Scott, 2004a); Tonzi Ranch, http://sites.ameriflux. lbl.gov/US-Ton/, (Baldocchi, 2001); Vaira Ranch, http://sites.ameriflux.lbl.gov/US-Var/ (Baldocchi, 2000); and Walker Branch, http://sites.ameriflux.lbl.gov/US-WBW/ (Meyers, 1995).

Acknowledgements. The authors would like to thank NASA for support of this research (NNH13AW37I). They would also like to acknowledge the Ameriflux network and the investigators who contributed the data used in this study. Funding for Ameriflux is provided by the US Department of Energy's Office of Science. The USDA is an equal opportunity employer.

Edited by: M. Coenders-Gerrits

Reviewed by: E. E. Aalbers and one anonymous referee

\section{References}

Abdelghani, C., Hoedjes, J. C. B., Rodriquez, J.-C., Watts, C. J., Garatuza, J., Jacob, F., and Kerr, Y. H.: Using remotely sensed data to estimate area-averaged daily surface fluxes over a semiarid mixed agricultural land, Agr. Forest Meteorol., 148, 330342,2008

Abu-Hamdeh, N. H.: Thermal Properties of soils as affected by density and water content, Biosyst. Eng., 86, 97-102, 2003.
Alfieri, J. G., Blanken, P. D., Yates, D. N., and Steffen, K.: Variability in the Environmental Factors Driving Evapotranspiration from a Grazed Rangeland during Severe Drought Conditions, J. Hydrometeorol., 8, 207-220, 2007.

Allen, R. G., Pereira, L. S., Raes, D., and Smith, M.: Crop evapotranspiration, Guideline for computing crop water requirements, FAO irrigation and drainage paper no. 56, Rome, Italy, 326 pp., 1998.

Allen, R. G., Tasumi, M., and Trezza, R.: Satellite-based energy balance for mapping evapotranspiration with internalized calibration (METRIC)-model, J. Irrig. Drain. Eng.-ASCE, 133, 380394, 2007.

Alves, I. and Pereira, L. S.: Modeling surface resistance from climatic variables?, Agr. Water Manage., 42, 371-385, 2000.

Anderson, M. C., Norman, J. M., Mecikalski, J. R., Otkin, J. A., and Kustas, W. P.: A climatological study of evapotranspiration and moisture stress across the continental United States based on thermal remote sensing: 2. Surface moisture climatology, J. Geophys. Res., 112, D11112, doi:10.1029/2006JD007507, 2007.

Anderson, M. C., Hain, C., Wardlow, B., Pimstein, A., Mecikalski, J. R., and Kustas, W. P.: Evaluation of drought indices based on thermal remote sensing of evapotranspiration over the continental United States, J. Climate, 15, 2025-2044, 2011.

Anderson, M. C., Allen, R. G., Morse, A., and Kustas, W. P.: Use of Landsat thermal imagery in monitoring evapotranspiration and managing water resources, Remote Sens. Environ., 122, 56-65, 2012.

Anderson, M. C., Zolin, C. A., Sentelhas, P. C., Hain, H. R., Semmens, K., Tugrul Yilmaz, M., Gao, F., Otkin, J. A., and Tetrault, R.: The evaporative stress index as an indicator of agricultural drought in Brazil: An assessment based on crop yield impacts, Remote Sens. Environ., 174, 82-99, 2016.

Asner, G.: Biophysical and biochemical sources of variability in canopy reflectance, Remote Sens. Environ., 64, 234-253, 1998.

Baker, J. and Griffis, T.: AmeriFlux US-Ro1 Rosemount- G21, http: //sites.ameriflux.lbl.gov/US-Ro1/ (last access: 3 January 2017), doi:10.17190/AMF/1246092, 2002.

Baldocchi, D.: AmeriFlux US-Var Vaira Ranch, http: //sites.ameriflux.lbl.gov/US-Var/ (last access: 3 January 2017), doi:10.17190/AMF/1245984, 2000.

Baldocchi, D.: AmeriFlux US-Ton Tonzi Ranch, http://sites. ameriflux.lbl.gov/US-Ton/ (last access: 3 January 2017), doi:10.17190/AMF/1245971, 2001.

Baldocchi, D., Falge, E., Gu, L. H., Olson, R., Hollinger, D., Running, S., Anthoni, P., Bernhofer, C., Davis, K., Evans, R., Fuentes, J., Goldstein, A., Katul, G., Law, B., Lee, X., Malhi, Y., Meyers, T., Munger, W., Oechel, W., Paw, K. T., Pilegaard, K., Schmid, H. P., Valentini, R., Verma, S., Vesala, T., Wilson, K., and Wolfsy, S.: FLUXNET: A new tool to study the temporal and spatial variability of ecosystem-scale carbon dioxide, water vapor, and energy flux densities, B. Am. Meteorol. Soc., 82, 2415-2434, 2001.

Bastiaanssen, W. G. M., Menenti, M., Feddes, R. A., and Holtslag, A. A. M.: A remote sensing surface energy balance algorithm for land (SEBAL): 1. Formulation, J. Hydrol., 212-213, 198-212, 1998.

Bird, R. E. and Riordan, C.: Simple solar spectral model for direct and diffuse irradiance on horizontal and tilted planes at the 
earth's surface for cloudless atmosphere, J. Clim. Appl. Meteorol., 25, 87-96, 1986.

Blanken, P.: AmeriFlux US-NR1 Niwot Ridge Forest, http:// sites.ameriflux.lbl.gov/US-NR1/ (last access: 3 January 2017), doi:10.17190/AMF/1246088, 1998.

Brunsell, N.: AmeriFlux US-Kon Konza Prairie LTER, http:// sites.ameriflux.lbl.gov/US-Kon (last access: 3 January 2017), doi:10.17190/AMF/1246068, 2006.

Brutsaert, W.: On a derivable formula for longwave radiation from clear skies, Water Resour. Res., 11, 742-744, 1975.

Brutsaert, W. and Sugita, M.: Application of self-preservation in the diurnal evolution of the surface energy budget to determine daily evaporation, J. Geophys. Res., 97, 18377-18382, 1992.

Burt, J. E. and Barber, G. M.: Elementary statistics for Geographers. Guilford Press, New York, USA, 1996.

Cammalleri, C., Anderson, M. C., Gao, F., Hain, C. R., and Kustas, W. P.: A data fusion approach for mapping daily evapotranspiration at field scale, Water Resour. Res., 49, 4672-4686, 2013.

Cammalleri, C., Anderson, M. C., and Kustas, W. P.: Upscaling of evapotranspiration fluxes from instantaneous to daytime scales for thermal remote sensing applications, Hydrol. Earth Syst. Sci., 18, 1885-1894, doi:10.5194/hess-18-1885-2014, 2014.

Chavez, J. L., Neale, C. M. U., Prueger, J. H., and Kustas, W. P.: Daily evapotranspiration estimates from extrapolating instantaneous airborne remote sensing ET values, Irrigation Sci., 27, 6781, 2008.

Colaizzi, P. D., Evett, S. R., Howell, T. A., and Tolk, J. A.: Comparison of five models to scale daily evapotranspiration from onetime-of-day measurements, T. ASABE, 49, 1409-1417, 2006.

Crago, R.: Conservation and variability of the evaporative fraction during the daytime, J. Hydrol., 180, 173-194, 1996.

Crago, R. D. and Brutsaert, W.: Daytime evaporation and the selfpreservation of the evaporative fraction and the Bowen ratio, J. Hydrol., 178, 241-255, 1996.

De Boor, C.: A Practical Guide to Splines. Springer-Verlag, New York, USA, 1994.

de Fraiture, C. and Wichelns, D.: Satisfying future water demands for agriculture, Agr. Water. Manage., 97, 502-511, 2010.

Delogu, E., Boulet, G., Olioso, A., Coudert, B., Chirouze, J., Ceschia, E., Le Dantec, V., Marloie, O., Chehbouni, G., and Lagouarde, J.-P.: Reconstruction of temporal variations of evapotranspiration using instantaneous estimates at the time of satellite overpass, Hydrol. Earth Syst. Sci., 16, 2995-3010, doi:10.5194/hess-16-2995-2012, 2012.

Droogers, P., Immerzeel, W. W., and Lorite, I. J.: Estimating actual irrigation application by remotely sensed evapotranspiration observations, Agr. Water Manage., 97, 1351-1359, 2010.

Farah, H. O., Bastiaanssen, W. G. M., and Feddes, R. A.: Evaluation of the temporal variability of the evaporative fraction in a tropical watershed, Int. J. Appl. Earth Obs., 5, 129-140, 2004.

Farquhar, G. D. and Sharkey, T. D.: Stomatal conductance and photosynthesis, Annu. Rev. Plant Phys., 33, 317-345, 1982.

Friedl, M. A. and Davis, F. W.: Sources of variation in radiometric surface temperature over a tallgrass prairie, Remote Sens. Environ., 48, 1-17, 1994.

Gentine, P., Entekhabi, D., Chehbouni, A., Boulet, G., and Duchemin, B.: Analysis of evaporative fraction diurnal behavior, Agr. Forest Meteorol., 143, 13-29, 2007.
Gonzalez-Dugo, M. P., Neale, C. M. U., Mateos, L., Kustas, W. P., Prueger, J. H., Anderson, M. C., and Li, F.: A comparison of operational remote sensing-based models for estimating crop evapotranspiration, Agr. Forest Meteorol., 149, 1843-1853, 2009.

Gordon, L. J., Finlayson, C., and Falkenmark, M.: Managing water in agriculture for food production and other ecosystem services, Agr. Water. Manage., 97, 512-519, 2010.

Hawkins, B. A. and Porter, E. E.: Relative influences of current and historical factors on mammal and bird diversity patterns in deglaciated North America, Global Ecol. Biogeogr., 12, 475481, 2003.

Hoedjes, J. C. B., Chehbouni, A., Jacob, F., Ezzahar, J., and Boulet, G.: Deriving daily evapotranspiration from remotely sensed instantaneous evaporative fraction over olive orchard in semi-arid Morocco, J. Hydrol., 354, 53-64, 2008.

Howell, T. A.: Enhancing water use efficiency in irrigated agriculture, Agron. J., 93, 281-289, 2001.

Jackson, R. D., Hatfield, J. L., Reginato, R. J., Idso, S. B., and Pinter Jr., P. L.: Estimation of daily evapotranspiration from one timeof-day measurements, Agr. Water Manage., 7, 351-362, 1983.

Kalma, J. D., McVicar, T. R., and McCabe, M. D.: Estimating land surface evaporation: A review of methods using remotely sensed surface temperature data, Surv. Geophys., 29, 421-469, 2008.

Katul, G. G., Oren, R., Manzano, S., Higgins, C., and Parlange, M. B.: Evapotranspiration: A process driving mass transport and energy exchange in the soil-plant-atmosphere-climate system, Rev. Geophys., 50, RG3002, doi:10.1029/2011RG000366, 2012.

Kreft, H. and Jetz, W.: Global patterns and determinants of vascular plant diversity, P. Natl. Acad. Sci. USA, 104, 5925-5930, 2007.

Kustas, W. P., Prueger, J. H., Hatfield, J. L., Ramalingan, K., and Hipps, L. E.: Variability in soil heat flux from a mesquite dune site, Agr. Forest Meteorol., 103, 249-264, 2000.

Legates, D. R. and McCabe, G. R.: Evaluating the use of "goodnessof-fit" measures in hydrologic and hydroclimatic model validation, Water Resour. Res., 35, 233-241, 1999.

Lhomme, J.-P. and Elguero, E.: Examination of evaporative fraction diurnal behaviour using a soil-vegetation model coupled with a mixed-layer model, Hydrol. Earth Syst. Sci., 3, 259-270, doi:10.5194/hess-3-259-1999, 1999.

Litvak, M.: AmeriFlux US-FR2 Freeman Ranch Mesquite Juniper, http://sites.ameriflux.lbl.gov/US-FR2 (last access: 3 January 2017), doi:10.17190/AMF/1246054, 2004.

Lobell, D. B. and Asner, G. P.: Moisture effects on soil reflectance, Soil Sci. Soc. Am. J., 66, 722-727, 2002.

Lu, J., Tang, R., Tang, H., and Li, Z.-L.: Derivation of daily evaporative fraction based on temporal variations in surface temperature, air temperature, and net radiation, Remote Sensing, 5, 53695396, 2013.

Matamala, R.: AmeriFlux US-IB1 Fermi National Laboratory Agriculture, http://sites.ameriflux.lbl.gov/US-IB1 (last access: 3 January 2017), doi:10.17190/AMF/1246065, 2004.

Matamala, R.: AmeriFlux US-IB2 Fermi National Laboratory Prairie, http://sites.ameriflux.lbl.gov/US-IB2 (last access: 3 January 2017), doi:10.17190/AMF/1246066, 2005.

McCabe, M. F., Wood, E., Wojcik, R., Pan, M., Sheffeld, J., Gao, H., and $\mathrm{Su}, \mathrm{H}$.: Hydrological consistency using multi-sensor remote sensing data for water and energy cycle studies, Remote Sens. Environ., 112, 430-444, 2008. 
McNaughton, K. G.: Evaporation and advection I: evaporation from extensive homogeneous surfaces, Q. J. Roy. Meteor. Soc., 102, 181-191, 1976.

Meeus, J.: Astronomical algorithms, Willmann-Bell, Richmond, Virginia, USA, 1991.

Meyers, T.: AmeriFlux US-WBW Walker Branch, http://sites. ameriflux.lbl.gov/US-WBW/ (last access: 3 January 2017), doi:10.17190/AMF/1246109, 1995.

Meyers, T.: AmeriFlux US-Bo1 Bondville, http://sites. ameriflux.lbl.gov/US-Bo1 (last access: 3 January 2017), doi:10.17190/AMF/1246036, 1996.

Meyers, T.: AmeriFlux US-Bkg Brookings, http://sites. ameriflux.lbl.gov/US-Bkg (last access: 3 January 2017), doi:10.17190/AMF/1246040, 2004.

Meyers, T.: AmeriFlux US-ChR Chestnut Ridge, http://sites. ameriflux.lbl.gov/US-ChR (last access: 3 January 2017), doi:10.17190/AMF/1246044, 2005.

Midgley, G. F., Hannah, L., Millar, D., Rutherford, M. C., and Powrie, L. W.: Assessing the vulnerability of species richness to anthropogenic climate change in a biodiversity hotspot, Global Ecol. Biogeogr., 11, 445-451, 2002.

Moler, C.: Numerical Computing with Matlab, SIAM Publishing, Philadelphia, 2004.

Myneni, R., Ross, J., and Asner, G.: A review on the theory of photon transport in leaf canopies, Agr. Forest Meteorol., 45, 1-153, 1989.

Nichols, W. and Cuenca, R. H.: Evaluation of the evaporative fraction for parameterization of the surface, energy-balance, Water Resour. Res., 29, 3681-3690, 1993.

Novick, K. and Phillips, R.: AmeriFlux US-MMS Morgan Monroe, http://sites.ameriflux.lbl.gov/US-MMS/ (last access: 3 January 2017), doi:10.17190/AMF/1246080, 1999.

Otkin, J. A., Anderson, M. C., Hain, C., Svoboda, M., Johnson, D., Mueller, R., Tadess, T., Wardlow, B., and Brown, J.: Assessing the evolution of soil moisture and vegetation conditions during the 2012 United States flash drought, Agr. Forest Meteorol., 218219, 230-242, 2016.

Peng, J., Borsche, M., Liu, Y., and Loew, A.: How representative are instantaneous evaporative fraction measurements of daytime fluxes?, Hydrol. Earth Syst. Sci., 17, 3913-3919, doi:10.5194/hess-17-3913-2013, 2013.

Prueger, J. and Parkin, T.: AmeriFlux US-Br1 Brooks Field Site 10, http://sites.ameriflux.lbl.gov/US-Br1 (last access: 3 January 2017), doi:10.17190/AMF/1246038, 2001.

Qadir, M., Boers, T. M., Schubert, S., Ghafoor, A., and Murtaza, G.: Agricultural water management in water-starved countries: challenges and opportunities, Agr. Water Manage., 62, 165-85, 2003.

Raupach, M: Combination theory and equilibrium evaporation, Q. J. Roy. Meteor. Soc., 127, 1149-1181, 2001.

Ryu, Y., Baldocchi, D. D., Black, T. A., Detto, M., Law, B. E., Leuning, R., Miyata, A., Reichstein, M., Vargas, R., Ammann, C., Beringer, J., Flanagan, L. B., Gu, L., Hutley, L. B., Kim, J., McCaughey, H., Moors, E. J., Rambal, S., and Vesala, T.: On the temporal upscaling of evapotranspiration from instantaneous remote sensing measurements to 8-day mean daily-sums, Agr. Forest Meteorol., 152, 212-222, 2012.

Santanello, J. S. and Friedl, M. A.: Diurnal covariation in soil heat flux and net radiation, J. Appl. Meteorol., 42, 851-862, 2003.
Schultz, B. and De Wrachien, D.: Irrigation and drainage systems research and development in the 21 st century, Irrig. Drain. Sci., 51, 311-327, 2002.

Scott, R.: AmeriFlux US-SRM Santa Rita Mesquite, http:// sites.ameriflux.lbl.gov/US-SRM/ (last access: 3 January 2017), doi:10.17190/AMF/1246104, 2004a.

Scott, R.: AmeriFlux US-Wkg Walnut Gulch Kendall Grasslands, http://sites.ameriflux.lbl.gov/US-Wkg (last access: 3 January 2017), doi:10.17190/AMF/1246112, 2004b.

Scott, R.: AmeriFlux US-Whs Walnut Gulch Lucky Hills Shrub, http://sites.ameriflux.lbl.gov/US-Whs (last access: 3 January 2017), doi:10.17190/AMF/1246113, 2007.

Scott, R. L., Edwards, E. A., Shutleworth, W. J., Huxman, T., Watts, C., and Goodrich, D. C.: Interannual and seasonal variation in fluxes of water and carbon dioxide from a riparian woodland ecosystem, Agr. Forest Meteorol., 122, 65-84, 2014.

Seguin, B. and Itier, B.: Using midday surface-temperature to estimate daily evaporation from satellite thermal IR data, Int. J. Remote Sens., 4, 371-383, 1983.

Song, J.: Phenological influences of the albedo of prairie grasslands and crop fields, Int. J. Biometeorol., 42, 153-157, 1999.

Stoy, P., Oishi, C., and Novick, K.: AmeriFlux US-Dk3 Duke Forest, http://sites.ameriflux.lbl.gov/US-Dk3 (last access: 3 January 2017), doi:10.17190/AMF/1246048, 2001.

Suleiman, A. and Crago, R. D.: Hourly and daytime evapotranspiration from grassland using radiometric surface temperatures, Agron. J., 96, 384-390, 2004.

Suyker, A.: AmeriFlux US-Ne1 Mead, http://sites. ameriflux.lbl.gov/US-NE1/ (last access: 3 January 2017), doi:10.17190/AMF/1246084, 2001.

Tasumi, M., Allen, R. G., Trezza, R., and Wright, J. L.: Satellitebased energy balance to assess within-population variance of crop coefficient curves, J. Irrig. Drain., 131, 94-109, 2005.

Thenkabail, P. S., Hanjra, M. A., Dheeravath, V., and Gumma, M.: Global croplands and their water use from remote sensing and nonremote sensing perspectives, in: Advances in environmental remote sensing: sensors, algorithms and applications, edited by: Weng, Q., Taylor and Francis, CRC Press, Boca Raton, Florida, USA, 383-420, 2010.

Trefethen, L. N.: Approximation theory and approximation practice, SIAM books, Philadelphia, Pennsylvania, USA, 2013.

Twine, T. E., Kustas, W. P., Norman, J. M., Cook, D. R., Houser, P. R., Meyer, T. P., Prueger, J. H., Starks, P. J., and Wesely, M. L.: Correcting eddy covariance flux underestimates over a grassland, Agr. Forest Meteorol., 103, 279-300, 2000.

Van de Griend, A. A. and Owe, M.: Bare soil surface resistance to evaporation by vapor diffusion under semiarid conditions, Water Resour. Res., 30, 181-188, 1994.

Van Niel, T. G., McVicar, T. R., Roderick, M. L., van Dijk, A. I. J. M., Renzullo, L. J., and van Gorsel, E.: Correcting for systematic error in satellite-derived latent heat flux due to assumptions in temporal scaling: assessment from flux tower observations, J. Hydrol., 409, 140-148, 2011.

Van Niel, T. G., McVicar, T. R., Roderick, M. L., van Djik, A. I. J. M., Beringer, J., Hutley, L. B., and van Gorsel, E.: Upscaling latent heat flux for thermal remote sensing studies: Comparison of alternative approaches and correction of bias, J. Hydrol., 468469, 35-46, 2012. 
Vörösmarty, C. J., McIntyre, P. B., Gessner, M. O., Dudgeon, D., Prusevich, A., Green, P., Glidden, S., Bunn, S. E., Sullivan, C. A., Liermann, C. R., and Davies, P. M.: Global threats to human water security and river biodiversity, Nature, 467, 555-561, 2010.

Wallace, J. S.: Increasing agricultural water use efficiency to meet future food production, Agr. Ecosyst. Environ., 82, 105-19, 2000.

Walter, I. A., Allen, R. G., Elliott, R. L., Itenfisu, D., Brown, P., Jensen, M. E., Mecham, B., Howell, T. A., Snyder, R., Echings, S., Spofford, T., Hattendorf, M., Martin, D. L., Cuenca, R. H., and Wright, J. L.: The ASCE Standardized Reference Evapotranspiration Equation, Technical Committee report to the Environmental and Water Resources Institute of the American Society of Civil Engineers from the Task Committee on Standardization of Reference Evapotranspiration, Reston, VA, 173 pp., 2005.

Wang, K. and Dickinson, R. E.: A review of global terrestrial evapotranspiration: Observation, modeling, climatology, and climatic variability, Rev. Geophys., 50, RG2005, doi:10.1029/2011RG000373, 2012.
Williams, M., Malhi, Y., Nobre, A. D., Rastetter, B., Grace, J., and Pereira, P.: Seasonal variation in net carbon exchange and evapotranspiration in a Brazilian rain forest: a modelling analysis, Plant Cell Environ., 21, 953-968, 2003.

Willmott, C. and Matsuura, K.: Advantages of the mean absolute error (MAE) over the root mean square error (RMSE) in assessing average model performance, Climate Res., 30, 79-82, 2005.

Willmott, C., Robeson, S. M., and Matsuura, K.: A refined index of model performance, Int. J. Climatol., 32, 2088-2094, 2012.

Wilks, W. S.: Statistical Methods in the Atmospheric Sciences, Academic Press, Burlington, Massachusetts, USA, 2006.

Wittich, K. P.: Some simple relationships between land-surface emissivity, greenness and the plant cover fraction for use in satellite remote sensing, Int. J. Biometeorol., 41, 58-64, 1997.

Wood, J. and Lainhong, G.: AmeriFlux US-MOz Missouri Ozark Site, http://sites.ameriflux.lbl.gov/US-MOz/(last access: 3 January 2017), doi:10.17190/AMF/1246081, 2004.

Zhang, L. and Lemeur, R.: Evaluation of daily evapotranspiration estimates from instantaneous measurements, Agr. Forest Meteorol., 74, 139-154, 1995. 